\section{References}

1 Sheldon, J H, The Social Medicine of Old Age. London, Oxford University Press, 1948.

2 Exton-Smith, A N, in Care of the Elderly: Meeting the Challenge of Dependency, ed A N Exton-Smith and J Grimley Evans. London, Academic Press, in press.

3 Sheldon, J H, British Medical fournal, 1960, $2,1685$.

4 Sheldon, J H, Gerontologia Clinica, 1963, 5, 129.

5 Hasselkus, E R, and Shambes, G M, fournal of Gerontology, 1975, 30, 661.

6 Eysenck, H J, Fournal of Neurology and Psychiatry, 1943, 6, 22.

? Ingham, J G, Fournal of Mental Sciences, 1954, 100, 432

8 Furneaux, W D, International fournal of Clinical and Experimental Hypnosis, 1961, 9, 195.

9 Wright, B M, Fournal of Physiology, 1971, 218, 27P.
10 Snedecor, G W, and Cochran, W G, Statistical Methods, 6th edn. Ames Iowa, Iowa State University Press, 1967.

11 Wright, B M, personal communication, 1976

12 Brocklehurst, J C, et al, Fracture of the femoral neck; a two centre survey of aetiological factors. In preparation.

13 Caird, F I, Andrews, G R, and Kennedy, R D, British Heart fournal, 1973, 35, 527.

14 Johnson, R H, et al, Lancet, 1965, 1, 731.

15 Miles, R, fournal of Industrial Hygiene, 1922, 3, 316

16 Smith, J W, Fournal of Anatomy, 1957, 91, 545.

17 Thomas, D P, and Whitney, R H, fournal of Anatomy, 1959, 93, 524.

18 Stevens, D L, and Tomlinson, G E, Proceedings of the Royal Society of Medicine, 1971, 64, 653.

(Accepted 8 December 1976)

\title{
Evaluation of ${ }^{125}$ I-fibrinogen test for venous thrombosis in patients with hip fractures: comparison between isotope scanning and necropsy findings
}

\author{
G K MORRIS， J R A MITCHELL
}

British Medical fournal, 1977, 1, 264-266

\begin{abstract}
Summary
The results of ${ }^{125}$ I-fibrinogen leg scanning during life were compared with the findings at a detailed post-mortem dissection of the leg veins in 31 patients with hip fractures who died during the period of isotope scanning or within seven days of the last scan. Thigh scanning on the side of the hip fracture proved valueless, and criteria for the confident isotopic diagnosis of venous thrombosis in the uninjured thigh could not be determined. In the lower leg a difference in uptake of $20 \%$ or more that persisted for 24 hours between adjacent positions on one leg or between corresponding positions on the two legs was consistently associated with the presence of venous thrombosis at necropsy.
\end{abstract}

\section{Introduction}

The ${ }^{125}$ I-fibrinogen test for deep vein thrombosis has been used as an objective diagnostic aid in many clinical trials of potential antithrombotic agents, and the ability of agents to suppress isotopically diagnosed thrombosis has been used as a trial endpoint. During the past decade various criteria have been used $^{1-6}$ to diagnose deep vein thrombosis but the most common are those that require a difference in uptake ${ }^{2}$ of $15 \%$ or $20 \%$ between adjacent positions on the same limb or between corresponding positions on the two limbs that persists for 24 hours or more. Close correlations between the results of scanning and venography have been found with both criteria, ${ }^{4}{ }^{78}$ but the correlations have related mostly to calf vein thrombosis. Browse et $a l,{ }^{5}$ however, found a good correlation between the results of

University Department of Medicine, General Hospital, Nottingham, NG1 6HA

G K MORRIS, MD, MRCP, senior lecturer in medicine

J R A MITCHELL, MD, FRCP, professor of medicine scanning and venography in the middle and distal thirds of the thigh as well as in the calf in established venous thrombosis.

Assessments of the isotope method, using venography as a yardstick, have mainly been carried out in general surgical patients and there has been only a limited evaluation of the ${ }^{125}$ I-fibrinogen test in patients subjected to leg surgery in whom high counts will occur near the operation site even in the absence of venous thrombosis. The two studies in which the ${ }^{125}$ I-fibrinogen test and venography have been compared in patients with hip fractures or hip replacements have shown that either the isotope test overdiagnoses or venography underdiagnoses venous thrombosis ${ }^{910}$ in these patients. Our study was undertaken to validate the results of scanning against the necropsy findings in patients with hip.fractures to determine the limitations of the ${ }^{125}$ I-fibrinogen test in such patients and to calibrate the test, if possible, for use in patients with hip fractures.

\section{Methods}

During a series of clinical trials in which the ${ }^{125}$ I-fibrinogen test was used in over 300 patients with hip fractures 1131 patients died during the scanning period or within seven days of the last scan. Detailed dissection of the leg veins was performed in those patients so that the results of isotope scanning during life could be compared with the necropsy findings.

${ }^{125}$ I-fibrinogen scanning technique-Supplies of ${ }^{125} I$-fibrinogen were obtained from the Radiochemical Centre, Amersham. Each patient received an intravenous injection of $100 \mu \mathrm{Ci}$ of the labelled fibrinogen after the thyroid gland uptake had been suppressed by an intravenous injection of sodium iodide $(100 \mathrm{mg})$. Oral sodium iodide $(100 \mathrm{mg})$ was then administered twice daily for 28 days thereafter. The isotope was injected as soon as possible after admission, and the injection was never delayed more than 48 hours after the patient's admission to hospital. Scanning with a Nuclear Enterprises Scaler/Ratemeter (fitted with a GP7 scintillation probe) was performed daily thereafter, omitting weekends, for 10 days or until the patient died. At the initial examination the maximum count over the heart was obtained and this position was marked so that subsequent praecordial counts could be obtained from the same position. Counting positions on the legs were also marked; these positions were at $5-\mathrm{cm}$ intervals from the midinguinal point down the medial aspect of the thigh over the course of the femoral vein and down the posterior aspect of the calf from the popliteal fossa to the ankle. 
To avoid the effects of venous pooling the legs were examined with the foot supported on a special stand which raised the leg by $30^{\circ}$. At each examination the count rate at the marked position on the precordium was recorded for two 10 -second periods and a mean rate was calculated. The count rate at each position on the leg was also expressed as the mean of two 10 -second counting periods. The mean count rate at each position on the leg was then expressed as a percentage of the mean praecordial count on that day, and this value was referred to as the "percentage uptake."

Dissection of leg veins-A long oblique incision was made from a point about four inches above the inguinal ligament; the incision crossed the inguinal ligament at its midpoint and continued down the medial aspect of the thigh over the adductor canal and ended just above the level of the medial femoral condyle. The common femoral, profunda femoral, cruciate, and superficial femoral veins and the upper part of the long saphenous vein were identified and opened as far as possible by slitting with scissors. The body was then turned face downwards and the incision at the superomedial aspect of the knee was continued obliquely behind the knee to expose the popliteal vein. A long midline incision was then made down the posterior aspect of the calf muscles to expose the deep posterior compartment. The popliteal and posterior tibial veins were opened by slitting with scissors. The intramuscular veins were examined for thrombi by making deep transverse cuts through the calf muscles at $2 \cdot 5-\mathrm{cm}$ intervals.

Identification of venous thrombus-Venous thrombus was identified macroscopically when a portion of the intravascular mass was loosely or firmly adherent to the vessel wall and when its surface had a rough granular appearance or when multiple white surface lines (lines of Zahn) were clearly seen. Post-mortem clot was recognised by its shiny non-adherent nature and by the fact that it was homogeneous except for a layer of clotted plasma. Histologically, thrombus was recognised by a laminated appearance in which red cells, white cells, and platelets (or disintegrated platelet material) were seen within a scaffold of coarse fibrin meshes. Histologically, post-mortem clot was recognised by the presence of blood cells in the ratio normally found in whole blood and by fibrin in the form of fine fibrillary strands.

\section{Results and comment}

Nineteen of the 31 necropsies were performed on patients who had died during the scanning period (providing 38 legs for study) and 12 on patients who had died within one week of the last scan (24 legs). The mean interval between the last scan and death in these 12 patients was $4 \cdot 1$ days.

Correlation between ${ }^{125}$ I-fibrinogen scan and necropsy findings in lower leg-Comparison of necropsy findings with scan results in the 62 lower legs (table I) indicated that venous thrombosis was present in all the 25 legs in which scanning had shown a difference in uptake of $20 \%$ or greater between adjacent positions on the same leg or between corresponding positions on the two legs that had persisted for at least 24 hours. In the 37 legs in which the difference in uptake had been less than $20 \%$ thrombus was present in six $(16 \%)$.

TABLE I-Correlation between scan results and necropsy findings in lower leg

\begin{tabular}{l|c|c|c|c|c|c|c}
\hline Difference in uptake $(\%):$ & $5-9$ & -14 & -19 & -24 & -29 & -34 & $\geqslant 35$ \\
\hline $\begin{array}{c}\text { No of lower legs dissected } \\
\text { No with venous thrombosis } \\
\text { at necropsy }\end{array}$ & 22 & 9 & 6 & 8 & 3 & 5 & 9 \\
\end{tabular}

Thigh scanning on side of the hip fracture-Thigh scanning on the side of the hip fracture produced much greater percentage uptakes than those on the opposite thigh. At necropsy these high values were found to be due to haematomas within the thigh muscles, which, though of variable extent, were a common post-mortem finding. Because of the high background counts attributable to these haematomas it was not reasonable to compare percentage uptakes at similar positions on the two thighs.

Comparison of uptakes at adjacent positions on the side of the hip fracture showed that differences as low as $7 \%$ were observed in patients who were shown to have thigh vein thrombosis at necropsy. Conversely, differences in adjacent site uptake of up to $79 \%$ were seen in patients who did not have venous thrombosis at necropsy. We concluded, therefore, that thigh scanning on the side of hip fracture was valueless.
Thigh scanning on side opposite to the hip fracture-Venous thrombosis in the non-fractured thigh was shown at necropsy in six of the 31 patients. A comparison between the maximum differences in percentage uptake between adjacent positions on scanning the thigh during life and the necropsy findings in each of these six cases is shown in table II. Analysis of the scanning results in the remaining 25 patients indicated that a difference in uptake of greater than $40 \%$ between adjacent positions could occur in the absence of venous thrombosis at necropsy. Thus, in contrast to the lower leg, there was no dividing line that would allow thigh vein thrombosis to be confidently diagnosed on the basis of an isotopic criterion. This assessment, however, takes into account percentage uptakes at positions on the thigh from immediately below the inguinal ligament to just above the medial femoral condyle. High counts are known to occur normally in the upper third of the thigh because of the proximity of the major arteries and veins at this level, and we therefore analysed the results from the distal two-thirds of the thigh separately. The only patient with a difference in uptake of greater than $20^{\circ}$ had extensive venous thrombosis. In the other five patients with venous thrombosis in the non-fractured thigh the maximum difference between adjacent positions in the distal two-thirds of the thigh did not exceed $19 \%$ We were forced to conclude that thigh scanning, even on the uninjured side, does not provide a reliable means of diagnosing venous thrombosis.

TABLE II-Maximum differences in percentage uptake between adjacent positions on non-fractured thigh in relation to necropsy findings

\begin{tabular}{|c|c|c|}
\hline $\begin{array}{l}\text { Case } \\
\text { No }\end{array}$ & $\begin{array}{l}\text { Maximum difference } \\
\text { in uptake between } \\
\text { adjacent scanning } \\
\text { sites }\left({ }_{0}^{\circ}\right)\end{array}$ & Necropsy findings \\
\hline 1 & 9 & $\begin{array}{l}\text { Small profunda vein thrombus (about } \\
5 \mathrm{~cm} \text { long) }\end{array}$ \\
\hline $\begin{array}{l}2 \\
3 \\
4 \\
5\end{array}$ & $\begin{array}{l}16 \\
19 \\
26 \\
25\end{array}$ & $\begin{array}{l}\text { Profunda vein thrombosis } \\
\text { Profunda and superficial femoral vein }\end{array}$ \\
\hline 6 & 45 & $\begin{array}{l}\text { Extensive thrombosis affecting all thigh } \\
\text { and pelvic veins }\end{array}$ \\
\hline
\end{tabular}

\section{Discussion}

Our studies show that thigh scanning on the side of a hip fracture is valueless, and we have insufficient data to establish clear-cut criteria for the isotopic diagnosis of venous thrombosis in the distal two-thirds of the non-fractured thigh. In the lower leg, however, a difference in uptake of $20 \%$ or more between adjacent positions on one leg or between corresponding positions on the two legs which persisted for at least 24 hours always indicated venous thrombosis. The selection of this endpoint underestimates the incidence of venous thrombosis, although the six false-negative cases might have been due to the inclusion in our study of patients who died up to seven days after the last scan and who might therefore have developed their venous thrombosis after the scan had given a correctly negative result. If the ${ }^{125} \mathrm{I}$-fibrinogen test is used to evaluate treatment in patients with hip fractures then lower leg scans that are judged normal or abnormal on the $20 \%$ criterion will provide a valid endpoint.

That the accuracy of the ${ }^{125}$ I-fibrinogen test is limited to the lower leg in patients with hip fractures is an obvious disadvantage, for the detachment of thrombi from the large veins of the thigh and pelvis probably causes the more serious and potentially lethal forms of pulmonary embolism. Nevertheless, thrombosis in the lower leg veins was invariably present in those patients in whom thigh vein thrombosis was shown at necropsy, and our studies lend support to the view that while venous thrombosis may develop multicentrically in the lower limb it is the calf veins that are most often affected. Browse $e t a^{12}$ showed a significant correlation between isotopically diagnosed calf vein thrombosis and pulmonary embolism diagnosed by ventilation-perfusion scanning, and we have found that treatment with warfarin sodium, which significantly reduces the frequency of isotopically diagnosed venous thrombosis in the lower leg, also eliminates pulmonary embolism. ${ }^{11}$ 
We thank all the orthopaedic surgeons at the Nottingham General Hospital for their close co-operation and for permission to study their patients and the pathologists who allowed us to perform the necropsy studies.

The study was supported by a grant for technical help and for the purchase of equipment from Boehringer Ingelheim Ltd, and we gratefully acknowledge their help.

Requests for reprints should be addressed to Dr G K Morris.

\section{References}

1 Atkins, P, and Hawkins, L A, Lancet, 1965, 2, 1217.

2 Negus, D, et al, British fournal of Surgery, 1968, 55, 835.
3 Kakkar, V V, et al, Lancet, 1970, 1, 540

${ }^{4}$ Milne, R M, et al, Lancet, 1971, 2, 445.

5 Browse, N L, et al, British Medical fournal, 1971, 4, 325.

${ }^{6}$ Myrvold, H E, et al, Acta Chirurgica Scandinavica, 1973, 139, 609.

${ }^{7}$ Flanc, C, Kakkar, V V, and Clarke, M B, British fournal of Surgery, 1968, $55,742$.

${ }^{8}$ Kakkar, V V, in Thromboembolism: Diagnosis and Treatment, ed V V Kakkar and A J Jouhar, p 107. Edinburgh and London, Churchill Livingstone, 1972.

${ }^{9}$ Barrie, W W, et al, British Medical fournal, 1974, 4, 130.

10 Louden, J R, British Medical fournal, 1976, 2, 793.

${ }_{11}$ Morris, G K, and Mitchell, J R A, Lancet, 1976, 2, 869.

12 Browse, N L, Clemenson, G, and Croft, D N, British Medical fournal, 1974, 1, 603.

(Accepted 23 November 1976)

\title{
Fibreoptic endoscopic palliative intubation of inoperable oesophagogastric neoplasms
}

\author{
MICHAEL ATKINSON, ROGER FERGUSON
}

British Medical fournal, 1977, 1, 266-267

\begin{abstract}
Summary
Palliative intubation for inoperable malignant strictures at the cardia was done on 16 occasions in 13 patients using fibreoptic endoscopy. Preliminary dilatation was performed, and the Celestin tube was mounted on an introducer and passed over a guide wire inserted with a fibreoptic endoscope. Only one death resulted from the procedure and all the 12 patients who left hospital were swallowing satisfactorily on discharge. The method provided a simple and relatively safe means of relieving dysphagia and improving nutrition.
\end{abstract}

\section{Introduction}

Neoplasms arising at or near the cardia carry a poor prognosis. Brookes $e t a l^{1}$ found patients with adenocarcinoma to have a worse outlook when this was at the cardia than when elsewhere in the stomach, and radical resection was possible in only $38.2 \%$ of their patients. The outlook for those with squamous carcinoma affecting the cardia is marginally better, ${ }^{2}$ but even so palliative treatment alone is possible in only half the patients. Rapidly progressive dysphagia is a distressing symptom demanding urgent relief if the patient is to be maintained in comfort and nutritional balance. Intubation with a funnel-ended tube pulled through the cardia at laparotomy is usually effective, ${ }^{3}{ }^{4}$ but the procedure carries a hospital mortality of about $25 \%$. This led us to explore the possibility of endoscopic intubation, so avoiding laparotomy. We describe here 16 intubations in 13 patients with neoplasms at the cardia.

\section{Patients and methods}

The 13 patients all had neoplasms occluding the cardia but in some the growth extended well up the oesophagus. The residual lumen was

General Hospital, Nottingham

MICHAEL ATKINSON, MD, FRCP, consultant physician ROGER FERGUSON, MB, MRCP, senior medical registrar usually less than $5 \mathrm{~mm}$ in diameter. Adenocarcinoma was present in 10 patients and squamous carcinoma in three. All were judged inoperable because of distant metastases or gross debility, and in one patient the growth had recurred after resection three years previously.

The diagnosis was confirmed histologically at preliminary endoscopy. General anaesthesia was used for all intubations. Under direct vision using the Olympus GIFK endoscope a guidewire was inserted through the malignant stricture into the stomach, and the lumen was dilated by passing Eder-Puestow olive dilators along the wire. The scope was passed through the stricture to assess its extent and relation to the diaphragm. In the light of this information a large-diameter Celestin tube was cut to an appropriate length and mounted on an Eder-Puestow dilator carrying a bougie just small enough to be withdrawn through the tube (see figure). A rammer, consisting of heavy duty polyvinylchloride tubing of $16 \mathrm{~mm}$ external diameter and $10 \mathrm{~mm}$ bore with a metal cone at its leading end to fit into the funnel of the Celestin tube, was mounted on the Eder-Puestow introducer and held in position by a screw clamp at its proximal end. After smearing with lubricating jelly the whole assembly was passed along the guidewire under radiological control, until its position was judged satisfactory. The screw clamp was released and the dilator with the guidewire was drawn back through the tube, which was held in place by the rammer. The rammer was finally withdrawn, leaving the Celestin tube in position.

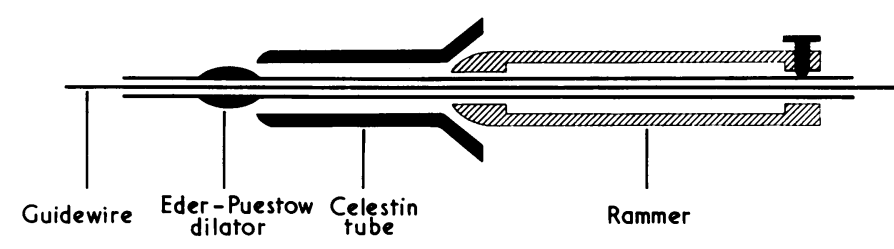

Celestin tube mounted on introducer.

The next morning a lateral chest radiograph was taken to check that the tube was in the correct position, and the patient was then allowed a soft diet washed down by effervescent drinks. On the following day a barium swallow examination was done to check that the tube was functioning normally. The patient was then allowed a more normal diet, depending on his masticatory capacity. Discharge from hospital was often possible within three days.

The degree of dysphagia was assessed before intubation, at the time of discharge from hospital, and at monthly intervals thereafter. Dysphagia was graded according to the diet the patient could take: $0=$ taking a normal diet; $1=$ unable to swallow certain solid foods 